\title{
ON SOME FRACTIONAL INTEGRO-DIFFERENTIAL INCLUSIONS WITH NONLOCAL MULTI-POINT BOUNDARY CONDITIONS
}

\author{
Aurelian CERnea
}

Abstract. Existence of solutions for two classes of fractional integro-differential inclusions with nonlocal multi-point boundary conditions is investigated in the case when the values of the setvalued map are not convex.

Mathematics subject classification (2010): 34A60, 34A08.

Keywords and phrases: Fractional derivative, differential inclusion, boundary conditions.

\section{REFERENCES}

[1] R. P. Agarwal, A. A. Saedi, A. A. Sharif And B. Ahmad, On nonlinear fractional-order boundary value problems with nonlocal multi-point conditions involving Liouville-Caputo derivative, Diff. Eqs. Appl. 9, (2017), 147-160.

[2] J. P. Aubin And H. Frankows Ka, Set-valued Analysis, Birkhauser, Basel, 1990.

[3] W. Benhamida, J. R. GRAEF AND S. HAMAni, Boundary value problems for Hadamard fractional differential equations with nonlocal multi-point boundary conditions, Frac. Diff. Calculus 8, (2018), $165-176$.

[4] D. Băleanu, K. Diethelm, E. Scalas and J. J. Trujillo, Fractional Calculus Models and Numerical Methods, World Scientific, Singapore, 2012.

[5] M. CAPuto, Elasticità e Dissipazione, Zanichelli, Bologna, 1969.

[6] A. CerneA, Filippov lemma for a class of Hadamard-type fractional differential inclusions, Fract. Calc. Appl. Anal. 18, (2015), 163-171.

[7] A. CERNEA, On the existence of solutions for a Hadamard-type fractional integro-differential inclusion, J. Nonlin. Anal. Optim. 6, (2015), 67-72.

[8] A. CERnEA, On some boundary value problems for a fractional integro-differential inclusion, Nonlin. Funct. Anal. Appl. 21, (2016), 215-223.

[9] K. Diethelm, The Analysis of Fractional Differential Equations, Springer, Berlin, 2010.

[10] A. F. FILIPPOV, Classical solutions of differential equations with multivalued right hand side, SIAM J. Control 5, (1967), 609-621.

[11] J. Hadamard, Essai sur l'etude des fonctions donnees par leur development de Taylor, J. Math. Pures Appl., 8, (1892), 101-186.

[12] A. Kilbas, H. M. SRivastava And J. J. Trujillo, Theory and Applications of Fractional Differential Equations, Elsevier, Amsterdam, 2006.

[13] K. Miller And B. Ross, An Introduction to the Fractional Calculus and Differential Equations, John Wiley, New York, 1993.

[14] I. Podlubny, Fractional Differential Equations, Academic Press, San Diego, 1999.

[15] Y. ZHOU, Fractional Evolution Equations and Inclusions. Analysis and Control, Academic Press, London, 2017. 